\title{
The Intangible Archive
}

\author{
Jeanie Sinclair \\ University College Falmouth \\ St Ives Archive \\ Js101092@falmouth.ac.uk
}

\author{
Philip Reeder \\ University College Falmouth \\ philipreeder@me.com
}

\begin{abstract}
The Intangible Archive, developed by art and design historian Jeanie Sinclair and sound artist Philip Reeder, combines locative technology with site-specific audio to create a hybrid method for the research and dissemination of the oral history archive. Often difficult to access, this paper hopes to demonstrate creative ways in which oral history can be relocated outside the archive.

This research examines notions of St Ives' 'creative community', rather than 'art colony', to describe the links (and disjunctions) between diverse creative practitioners, communities, places, and spaces in which they operate. Using the Memory Bay oral history archive in St Ives (a collaboration between University College Falmouth, Tate St. Ives, St. Ives Archive, Leach Pottery and Porthmeor Studios) has been a catalyst for on-going research exploring how art and cultural practice, past and present, connects individuals and communities, and how memory and identity is intertwined with and performed through space and place.
\end{abstract}

Mobile application, Pervasive Media, Playful, Sound, Locative Media

\section{INTRODUCTION}

The St Ives archive is an independent community archive, set up by the community, for the community, in 1996 to record and preserve the

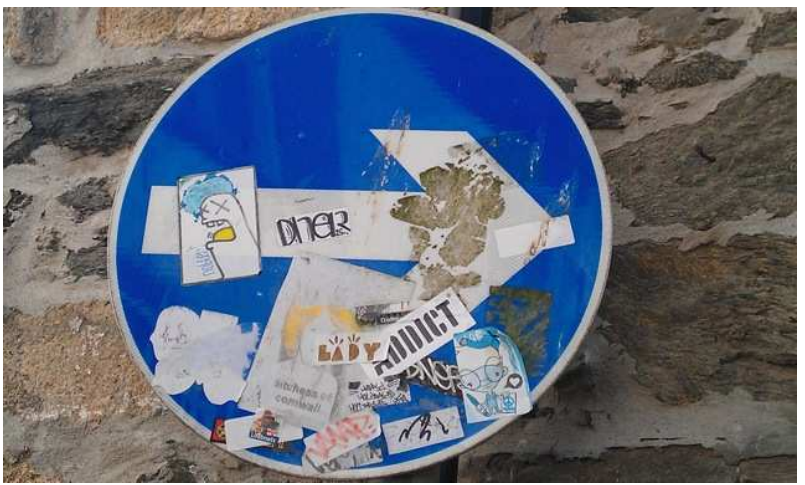

history of the town. The archive collects newspaper articles, maps, legal documents, correspondence, catalogues and pamphlets, books, sound recordings, photographs, and genealogical records. It is run by volunteers and funded by membership subscriptions and donations. In 2008, the Memory Bay oral history project, a partnership between the St Ives Archive, Tate St Ives, the Leach Pottery, Porthmeor Studios, University College Falmouth and the St Ives School of Painting, was successful in securing Heritage Lottery funding to create an archive of recordings of local people's memories of
St Ives' creative community. Visitors can currently come to the archive to listen to oral history from Memory Bay, as well as listening to short clips online. However, unlike museums, archives are hard to access, requiring permissions, appointments, and prior knowledge of the information sought.

We wanted to make the oral history archive more accessible to the general public. Inspired by the idea of the museum without walls, we wanted to create an archive without walls.

\section{KEY OBJECTIVES}

Our main aim was to produce a project that allowed people to access oral histories outside of the space of the archive. We wanted it to be simple, playful and engaging, using sound and movement to generate conversations around the idea of the archive, what it is for and the relationship between memory, history place and community.

We also wanted The Intangible Archive to be both a performance of the idea of the archival search, and a performance of the connections between community and place. 


\section{WALKING AS SEARCHING}

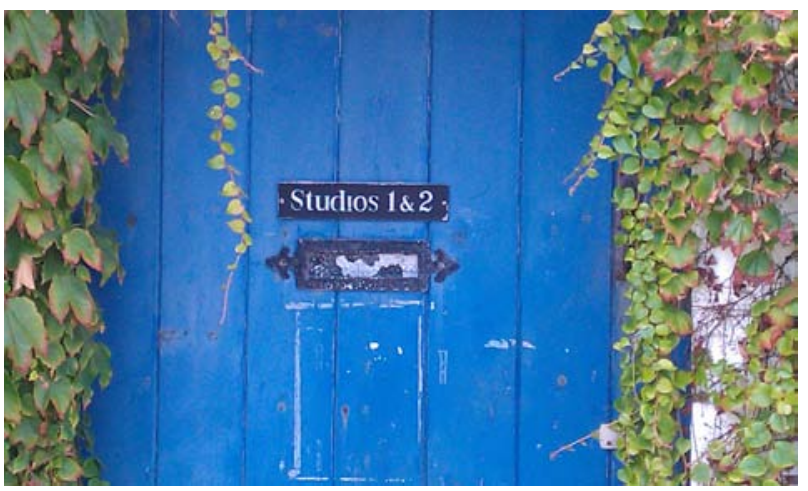

We chose the name 'The Intangible Archive' in order to emphasize that it is not simply a sound walk in the linear and temporal sense. Instead, it is a spatial experience, an archive without walls. Archival material is invisibly re-archived around the town, to be discovered by serendipitous encounter. The archive is extended beyond the building itself, enabling people to participate in the creation of their own stories from the archive.

'Intangible' is taken from the UNESCO definition of intangible cultural heritage where 'the practices, representations, expressions, knowledge, skills as well as the instruments, objects, artefacts and cultural spaces associated therewith - that communities, groups and, in some cases, individuals recognize as part of their cultural heritage. This intangible cultural heritage, transmitted from generation to generation, is constantly recreated by communities and groups in response to their environment, their interaction with nature and their history, and provides them with a sense of identity and continuity, thus promoting respect for cultural diversity and human creativity'. (UNESCO 2003)

The Intangible Archive is a performance the idea of an archival search. Instead of searching by using a catalogue or rifling through papers, the participants put on headphones connected to a Smartphone. They hear an ambient soundtrack, composed by sound artist Philip Reeder as they wander the streets of St Ives. On reaching certain points, GPS will activate voices from the archive. Rather than a linear walk that is time dependent, or an audio tour that tells participants the history of place, this allows the user to write their own history of place, defined by the way they walk around the town. Walking and searching become modes of storytelling, where each fragment of oral history is a quotation within each unique narrative constructed by the connections between each voice and the participants' own memory and experience of place. In the same way that historians piece together fragments from the archive, to create histories that are constantly rewritten, so The Intangible Archive has an infinite number of narratives of place to discover.

\section{SOUND \& PLACE-LISTENING}

Music fulfills a number of key roles in this project. A common design problem with GPS soundwalks, is how to signal to participants that they are "in" the soundwalk, and that it is functioning correctly. This initial layer of technical uncertainty that can be instilled in the user is a common issue. Participants can spend time checking devices and worrying if they are in the correct geographic location, which detracts from the immersive experience. This layer of technology is often obstructive, when it should be abstruse. Whilst some soundwalks create a signal that plays when participants are "out of bounds", this can have as negative an effect as the technological uncertainty. This is particularly strong if the "out of bounds" signal is not related thematically to the soundwalk. This background music allows the participants to become immersed in the soundwalk, confident both that the technology is functioning correctly, and that they are in a suitable location.

Thematically related music in this instance is that which reinforces the message of the interview audio. Creating music that incorporated harmony, melody and rhythm through instrumentation could perhaps have been successful. This could have been created by a composer, or taken the form of a recorded folk ensemble, for example. The bulk of meaning would have relied on abstract connections of form within the music, or on some extrinsic memory connection of the participant's that is invoked by the music. This sound-based music, on the other hand, allows an extra dimension. Instead of imposing abstract musical connections upon the participant, it functions rather like ambient music. As Brian Eno states, this music can be "actively listened to with attention or as easily ignored, depending on the choice of the listener" (Jarret 1998).

The Intangible Archive contains disparate voices, who speak of varying subjects in wide-ranging contexts. As the participants are often walking, the space around them also changes continuously. The sound-based music that is ambient and drone-like, exists as a bed on which the interview audio rests. It allows the heterogeneous nature of the foreground interview footage to be unified through a common existence in the space created by the music.

This notion of space provided by the music not only unifies the fragments of foreground interview audio, but also provides a different space in which the participant can exist. The ambience allows external 
world sounds (other people, traffic, seagulls, the sea) to be blended in, without the real world significantly disrupting the exploratory headphone space of the participant. This high level of immersion and connectivity can create a feeling of performance for the participant, and intensifies the experience of place. It also embeds further historical artifacts in the experience. The four pieces of in The Intangible Archive contain material recorded from the quinquennial ceremony commemorating the eccentric mayor of St Ives, John Knill. This material is merged with recordings from key locations around St Ives. Participants in the soundwalk are performing multiple layers of dispersed audio. They do not hear the interview material as isolated memories, rather they exist in the vessel of more coded, less intelligible historicity.

\section{CONSTRUCTING THE INVISIBLE ARCHIVE}

The fragments of oral history to be placed in The Intangible Archive were selected according to a number of factors. These included the quality of the voice itself, and practical concerns like the quality of the recording. Where the oral history contained stories related to a specific place, they were relocated geographically. Some recordings contained common themes; for example, Tate St Ives is mentioned frequently by different people. Where thematic connections arise, voices are placed in close proximity to each other, allowing participants to make their own connections between these voices, which often conflict and contradict.

Once locations had been decided, the first test version of The Intangible Archive was created using HP Labs MScape software. Its simple interface allows sound clips to be imported into a library, a GPS hotspot is drawn on to a map, then the sound clip is dragged and dropped onto the hotspot. Behaviours can then be defined simply from a drop down menu. More complex functions can be defined using JavaScript.

The main problem we had with this version is the accuracy of the maps. As MScapes is no longer supported, live map software was not available, and it was necessary to use an image from Google Earth and enter manual co-ordinates. With St Ives' narrow streets placing clips accurately proved problematic; combined with GPS drift throughout the day, there was no guarantee that all of the voices would be in the place they were intended to be in.

Our first public test for the St Ives September Festival provided essential feedback, leading to a rethink on how we described the project.

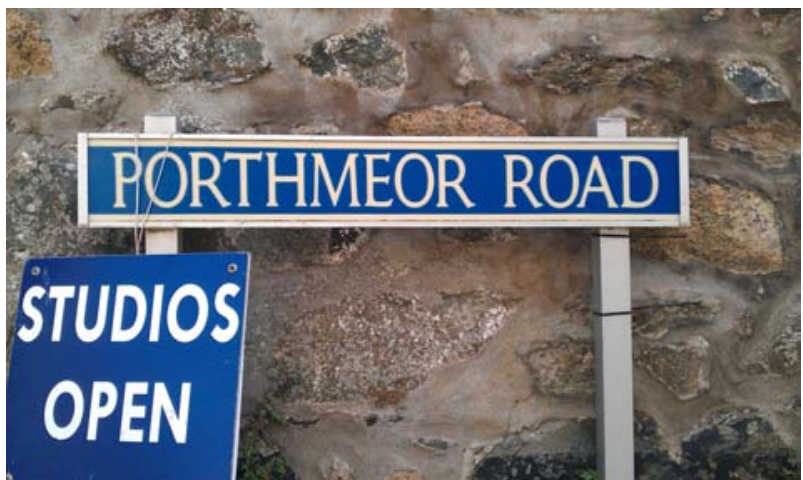

Participants were occasionally disappointed that it was not a straightforward audio history tour; others did not feel confident about walking without being told where to go, or given a map.

At this point we realised that we had not articulated that it was not a straightforward soundwalk, but was really echoing the idea of an archival search, and therefore was more of a treasure hunt.

For the next iteration, we used Calvium's Appfurnace to build a Smartphone application. With a slightly more complex interface and coding input, it required a higher level of programming skill, but is still accessible with a little instruction. However, as we only wanted to produce the same effect as with the mediascape version, it was simple to create functions in JavaScript to play and stop sounds on entering or leaving a hotspot. The maps are live, so significantly more effective than previously, allowing a far greater degree of accuracy.

The drawbacks with this version are the cost of publishing to Apple's App Store or Google's play shop, which although not enormous, are prohibitive without any funding. The other problem with publishing is that although we may be able to reach a wider audience, it's hard to monitor the experience and feedback from people using the app.

\section{CONCLUSION}

The Intangible Archive has achieved its aims so far, in allowing people to access oral history archives in a playful and engaging way. It allows participants to create their own unique histories of place as they walk, making connections between voices and places. There remain many further possibilities to expand the amount of material to be discovered in The Intangible Archive, and as more oral history recordings are made, there are more connections, and more narratives, to be added, as well as the possibility of using more complex programming to expand the ways in which archival material can be accessed. 


\section{REFERENCES}

UNESCO Article 2, Convention for the Safeguarding of Intangible Cultural Heritage 2003 http://www.unesco.org/culture/ich/index.php?lg=en $\& p g=00022 \#$ art2 (retrieved 31 March 2012)
Jarret, Michael, Sound Tracks: A Musical ABC. Temple University Press, 1998. 